\title{
Alterações morfológicas em epitélio lingual de camundongos expostos ao álcool etílico a $40^{\circ} \mathrm{GL}$ Morphological changes in epithelium of the tongue of mice exposed to $40^{\circ} \mathrm{GL}$ alcohol solution
}

\author{
*Sanfelice, J.C.; \\ **Padilha, D.M.P.; \\ ***Sant'Ana Filho, M.
}

\begin{abstract}
RESUMO
O álcool nunca foi apontado como um carcinógeno isoladamente, a literatura se refere ao álcool como um elemento que facilitaria a atuação de um carcinógeno ou um elemento que agiria em sinergia juntamente com o tabaco no desenvolvimento do câncer bucal. Buscando avaliar o papel do álcool como modificador da morfologia da mucosa da língua realizamos o experimento com 60 camundongos divididos em três grupos - Controle, Álcool Contínuo e Álcool Tópico - durante o período de um ano. Os animais do Grupo Álcool Contínuo seguiram com a alimentação normal tendo sido substituída a bebida por álcool a $40^{\circ} \mathrm{GL}$ e os do Grupo Álcool Tópico recebiam aplicação tópica de álcool $40^{\circ} \mathrm{GL}$ duas vezes por semana, simulando um consumo eventual. Através de amostras retiradas do dorso da língua, no início do experimento e depois a cada seis meses, fez-se a análise de alterações morfológicas no epitélio (espessura do epitélio, espessura da camada de ceratina, relação entre comprimento da camada basal e superficial e relação núcleo citoplasma das células do epitélio (camada basal e intermediária)). Através de análise estatística dos resultados verificamos alterações significativas em quase todos os itens avaliados. Concluímos que o álcool pode ser apontado como um agente modificador da morfologia da mucosa do dorso da língua quando ingerido ou aplicado topicamente.
\end{abstract}

\section{Palavras-Chaves: \\ Álcool, Morfologia lingual. Mucosa bucal. Cavidade bucal: Efeito do álcool}

\section{INTRODUÇÃO}

O etanol, álcool etílico ou simplesmente álcool é um líquido incolor e volátil com um odor característico que é principalmente produzido por meio da fermentação de açúcares ou carboidratos através da ação de microrganismos como bactérias e leveduras. É um líquido de natureza polar, solúvel em água, clorofórmio e acetona, entre outros solventes, e é praticamente insolúvel em gorduras e óleos. (KATO; NOMURA, 1994; MAIER et al., 1994; MIKAMI; HASEBA; OHNO, 1997; RIVEROS-ROSAS; JULIANSANCHEZ; PIN $\tilde{A}, 1997$; OGDEN; WIGTH, 1998; WIGTH; OGDEN, 1998;).

A taxa de mortalidade brasileira associada a neoplasia maligna de boca está entre as mais altas dentre 46 países avaliados pela Organização Mundial de Saúde (OMS) e a que responde pela maioria dos casos é o carcinoma epidermóide bucal (FRANCO, 1987; INSTITUTO NACIONAL DO CÂNCER, 2000).

Tanto como um fator isolado como quando associado com outros fatores a ingestão crônica de álcool parece estar relacionada com o desenvolvimento de câncer bucal em pacientes que são suscetíveis. $O$ consumo conjunto de álcool e tabaco faz aumentar ainda mais o risco de câncer bucal, de faringe e de laringe supraglótica. Mas o etanol já é apontado como um iniciador do processo de carcinogênese através de alterações celulares que pode causar e/ou predispor (MAIER; WEIDAUER, 1995; SIMANOWSKI et al., 1995; BORN et al.; 1996; SLOMIANY et al., 1998; OGDEN; WIGHT, 1998).

Embora Wigth e Ogden (1998) afirmem que o etanol puro nunca foi demonstrado como sendo um agente carcinogênico em experiências laboratoriais, bebidas alcoólicas são reconhecidas como sendo um importante fator etiológico no desenvolvimento de câncer bucal, mesmo que ainda não se conheça o mecanismo. Devemos considerar ainda que algumas bebidas possuem algumas impurezas e/ou contaminantes que poderiam ser carcinogênicos (KATO; NOMURA, 1994; OGDEN;WIGTH, 1998; WIGTH; OGDEN, 1998).

Sugere-se que o álcool aumenta a penetração de carcinógenos pela mucosa bucal, agindo ou por solubilização maior destes ou por aumento da permeabilidade da mucosa bucal (OGDEN; WIGTH, 1998; WIGTH; OGDEN, 1998). RIVEROS-ROSAS, JULIANSANCHEZ e PINÃ (1997) explicam a passagem do etanol através da mucosa e da membrana celular em razão do pequeno tamanho de sua molécula.

Squier, Cox e Hall (1986) buscando entender o mecanismo sinérgico existente na atuação do tabaco e álcool avaliaram a penetração de um carcinógeno do tabaco (nitrosonornicotina - NNN) na mucosa bucal associando-a ao álcool. Utilizando concentração de $5 \%$ e $50 \%$ de etanol, encontraram uma permeabilidade aumentada na mucosa do assoalho bucal apenas na concentração de $5 \%$, após várias pequenas exposições espaçadas ao etanol. A concentração de $50 \%$ não alterou significativamente a permeabilidade da mucosa, com exceção da mucosa jugal. Tais resultados indicam ser o assoalho bucal uma área de alto risco para o desenvolvimento de um carcinoma e que os fumantes e alcoolistas têm um risco relativo aumentado, especialmente aqueles que consomem bebidas com baixa concentração alcoólica - como é o caso da cerveja $(6 \%)$ e do vinho (10 a $11,5 \%)$. Os autores chamam a atenção de que a concentração de $5 \%$ de álcool é encontrada nos enxaguatórios bucais e também em alguns medicamentos infantis, como xaropes.

Resultados coincidentes foram encontrados por Du et al. (2000) que também estudaram a permeabilidade da mucosa bucal ao carcinógeno - nitrosonornicotina (NNN) associado ao etanol em diversas concentrações (de 5 a $50 \%$ ). Os autores explicam a redução na permeabilidade da mucosa na concentração de $50 \%$ de etanol por um efei-

* Mestre em Patologia Bucal - Rua Prof.Carvalho de Freitas, 737/204 P.Alegre RS juliosan@terra.com.br ** Doutora em Estomatologia - Rua Ramiro Barcelos, 2492 P.Alegre RS dpadilha@pro-via.rs.com.br *** Doutor em Estomatologia - Rua Ramiro Barcelos, $24925^{\circ}$ andar P.Alegre RS manoel@ufrgs.br 
to fixador deste sobre a mucosa e concluem que a associação etanol-nicotina aumenta significativamente a penetração de NNN na mucosa. Concluem, ainda, que os resultados deste estudo sugerem que se possa explicar a sinergia entre tabaco e álcool na etiologia do câncer bucal pela permeabilidade que o álcool provoca na mucosa permitindo e facilitando a entrada de carcinógenos do tabaco e outros através da mucosa bucal.

Maier et al. (1994) avaliando o efeito do uso crônico de álcool sobre a morfologia da mucosa bucal de ratos através de análise morfométrica, concluíram que o consumo crônico do álcool causa uma atrofia na mucosa bucal seguida de uma intensa proliferação da mucosa que está associada a uma suscetibilidade aumentada aos efeitos de carcinógenos químicos.

Oliveira et al. (1994) buscando avaliar morfometricamente as alterações no epitélio de língua dos fetos de ratas que receberam aguardente de cana concluíram que o alcoolismo materno durante a gestação induz retardo no crescimento e diferenciação celular no epitélio da língua do feto, com aumento do volume nuclear, citoplasmático e celular, diminuição da espessura do epitélio e da camada de ceratina, além da diminuição da densidade numérica celular.

Maier et al. (1999) estudando o efeito do consumo de álcool sobre a mucosa da região da glote de ratos encontraram uma redução significativa na espessura do epitélio desta região, tanto em sua comissura anterior como posterior, mas não encontraram diferenças entre os núcleos das células da camada basal dos ratos submetidos ao álcool e dos ratos controle. Concluem que a redução da espessura epitelial desta região pode sugerir uma maior facilidade de ação local de carcinógenos químicos.

\section{MATERIAL E MÉTODOS}

Foram utilizados 60 camundongos (Mus domesticus domesticus), da linhagem CF1, fêmeas, com dois meses de idade e peso médio inicial de 32 gramas, que foram adquiridos na Divisão de Produção e Experimentação Animal da Fundação Estadual de Produção e Pesquisa em Saúde - FEPPS.

Os camundongos foram separados em três grupos com 20 animais cada. $O$ primeiro foi identificado como GRUPO CONTROLE (GC), e seguiu com alimentação e bebida ad libitum. O segundo foi identificado como GRUPO ÁLCOOL CONTÍNUO (GAC), e foi submetido ao consumo contínuo de álcool etílico (Álcool etílico, P.A. - etanol absoluto marca Reagen ${ }^{\circledR}$ - fabricante Quimibrás Indústrias Químicas S.A. - Rio de Janeiro $\mathrm{RJ})$, na graduação de $40^{\circ} \mathrm{GL}$. 0 terceiro foi identificado como GRUPO ÁLCOOL TÓPICO (GAT), e recebeu aplicação tópica de álcool, na mesma graduação alcoólica do grupo álcool contínuo. A cavidade bucal foi irrigada com $01 \mathrm{ml}$ duas vezes por semana.

Foram avaliados, semanalmente, o volume (em mililitros) de água e de álcool etílico consumidos e o peso de ração consumida.

Uma amostra da mucosa lingual (dorso) foi removida utilizando-se um "punch" de 03 $\mathrm{mm}$ de diâmetro e fixada em formalina tamponada por 24 horas. Realizou-se esta coleta no início, no $6^{\circ}$ e no $12^{\circ}$ mês.

Ao final do período experimental os animais foram sacrificados, por deslocamento cervical com analgesia prévia, e dissecados, tendo sido recolhidos e guardados seus órgãos internos e esqueleto para análises futuras.

As peças fixadas foram processadas para inclusão em parafina e foram preparadas lâminas que receberam coloração por hematoxilina-eosina.

Para avaliação e quantificação dos itens propostos utilizou-se o Sistema de Processamento e Análise de Imagens IMAJELAB $^{\circledR}$ e o IMAGE-TOOL ${ }^{\circledR}$, associado a um microscópio para a captação das imagens microscópicas e sua transferência para o computador.

Para a realização da medição da espessura do epitélio realizou-se a captura de imagens de microscopia das lâminas utilizandose o aumento de 250 vezes. Utilizando-se a ferramenta de medição de retas do sistema IMAGELAB $^{\circledR}$, calibrado para o sistema métrico $(\mathrm{mm})$, tomávamos cinco pontos para a medição: uma medição em cada extremidade, uma no centro e outras duas localizadas na porção média entre cada uma das extremidades e o centro.

Para a realização do cálculo da relação núcleo-citoplasma realizou-se a captura de imagens com o aumento de 400 vezes. De cada lâmina obteve-se duas imagens diferentes e em cada uma dessas realizou-se a tomada da área de dez células diferentes distribuídas na camada basal e intermediária do epitélio. A relação núcleo- citoplasma era calculada dividindo-se o valor da área do núcleo pelo valor da área do citoplasma.
Quanto mais próximo de um esta relação maior é o núcleo celular.

Para a realização da medição da espessura da camada de ceratina realizou-se a captura de imagens com o aumento de 320 vezes, e selecionou-se uma área do epitélio aleatoriamente onde fosse possível ver-se toda a espessura do epitélio e a camada de ceratina. Cinco pontos para a medição foram tomados ao longo de toda a imagem da camada de ceratina, distribuídos da seguinte forma: uma medição em cada extremidade, uma no centro e outras duas localizadas na porção média entre cada uma das extremidades e o centro.

Para a realização da medição da relação entre o comprimento da camada basal e superficial do epitélio foram utilizadas as mesmas imagens utilizadas no cálculo da espessura da camada de ceratina. Toda a extensão da camada basal e superficial eram mensuradas através da tomada de segmentos consecutivos e interligados reproduzindose assim a irregularidade de cada uma das regiões.

Este trabalho está de acordo com a Declaração Universal dos Direitos Animais e os princípios éticos na experimentação animal emitidos pelo Código Brasileiro de Experimentação Animal (GOLDIM, 1997) e recebeu parecer favorável da Comissão de Ética da Faculdade de Odontologia em 27 de Janeiro de 2001 conforme Processo n. ${ }^{\circ}$ PPGO 40/99.

\section{RESULTADOS}

- DA RELAÇÃO ENTRE O COMPRIMENTO DA CAMADA BASAL E SUPERFICIAL

A mensuração desta relação é entendida por nós como um indicador do índice de proliferação do epitélio e é considerada pela razão entre o comprimento da camada basal dividido pelo comprimento da camada superficial, quanto maior o valor, maior é a camada basal e com isso maior a área de proliferação epitelial.

Tabela 1. Comparação da relação entre o comprimento da camada basal e superficial do epitélio, entre os grupos, no momento inicial.

\begin{tabular}{|lcccc|}
\hline Grupo & Média & Desvio-Padrão & Rank Médio & p \\
\hline Controle & 1,08 & 0,24 & 30,50 & 0,356 \\
Álcool Contínuo & 1,12 & 0,29 & 30,00 & \\
Álcool Tópico & 1,00 & 0,25 & 23,74 & \\
\hline
\end{tabular}

teste não-paramétrico de Kruskal-Wallis

Os dados apresentados nos mostram que não houve diferença entre os grupos, no momento inicial, pois não foram verificadas diferenças estatísticas significativas na relação entre o comprimento da camada basal e superficial do epitélio entre os grupos estudados. Fato que era esperado sendo este o momento inicial do experimento e ainda não havíamos exposto os animais às variáveis (álcool e tempo). 
Tabela 2. Comparação da relação entre o comprimento da camada basal e superficial do epitélio, entre os grupos, no momento 6 meses

\begin{tabular}{|lcccc|}
\hline Grupo & Média & Desvio-Padrão & Rank Médio & p \\
\hline Controle & 1,38 & 6,36 & 31,56 & 0,06 \\
Álcool Contínuo & 1,16 & 4,81 & 24,13 & \\
Álcool Tópico & 1,05 & 6,16 & 19,65 & \\
\hline
\end{tabular}

teste não-paramétrico de Kruskal-Wallis

Tabela 3. Comparação da relação entre o comprimento da camada basal e superficial do epitélio, entre os grupos, no momento 12 meses

\begin{tabular}{|lcccc}
\hline Grupo & Média & Desvio-Padrão & Rank Médio & p \\
\hline Controle & 1,27 & 0,35 & 23,88 & 0,824 \\
Álcool Contínuo & 1,21 & 0,32 & 21,71 & \\
Álcool Tópico & 1,27 & 0,36 & 24,73 & \\
\hline
\end{tabular}

teste não-paramétrico de Kruskal-Wallis

Tabela 4. Comparação da relação entre o comprimento da camada basal e superficial do epitélio, entre os tempos, no grupo controle

\begin{tabular}{|lcccc|}
\hline Biópsia & Média & Desvio-Padrão & Rank Médio & p \\
\hline Biópsia Inicial & 1,08 & 0,24 & 19,61 & 0,06 \\
Biópsia 6 meses & 1,39 & 0,46 & 31,44 & \\
Biópsia 12 meses & 1,27 & 0,35 & 27,65 & \\
\hline
\end{tabular}

teste não-paramétrico de Kruskal-Wallis

Tabela 5. Comparação da relação entre o comprimento da camada basal e superficial do epitélio, entre os tempos, no grupo álcool contínuo.

\begin{tabular}{|lcccc|}
\hline Biópsia & Média & Desvio-Padrão & Rank Médio & p \\
\hline Biópsia Inicial & 1,12 & 0,29 & 22,33 & 0,67 \\
Biópsia 6 meses & 1,16 & 0,32 & 25,00 & \\
Biópsia 12 meses & 1,21 & 0,32 & 26,71 & \\
\hline
\end{tabular}

Conforme os dados da Tabela 2 podemos observar que também, no momento de 6 meses, não foram verificadas diferenças estatísticas significativas na relação entre o comprimento da camada basal e superficial do epitélio entre os grupos estudados.

Da mesma forma, os dados apresentados na Tabela 3 nos mostram que não foram verificadas diferenças estatísticas significativas na relação entre o comprimento da camada basal e superficial do epitélio entre os grupos estudados.

A observação dos dados apresentados na Tabela 4 nos mostra que houve variação da relação entre o comprimento da camada basal e superficial do epitélio estudada ao longo do tempo no Grupo Controle, mas esta não foi estatisticamente significativa.

Também, assim como na Tabela 4 , vemos pelos dados apresentados na Tabela 5 que a relação entre o comprimento da camada basal e superficial do epitélio no Grupo Álcool Contínuo ocorreu ao longo do período experimental, mas não foi estatisticamente significativa.

Podemos observar através dos resultados na Tabela 6 que foram verificadas diferenças estatísticas significativas na relação entre o comprimento da camada basal e superficial do epitélio para os tempos estudados no Grupo Álcool Tópico. Observa-se que o valor da relação é superior na biópsia de 12 meses $(p=0,03)$.

Podemos observar o que os dados nos mostram através da imagem da figura 1 que mostra uma fotomicrografia do Grupo Álcool Tópico no momento de 12 meses.

teste não-paramétrico de Kruskal-Wallis

Tabela 5. Comparação da relação entre o comprimento da camada basal e superficial do epitélio, entre os tempos, no grupo álcool contínuo.

\begin{tabular}{|lcccc}
\hline Biópsia & Média & Desvio-Padrão & Rank Médio & p \\
\hline Biópsia Inicial & 1,12 & 0,29 & 22,33 & 0,67 \\
Biópsia 6 meses & 1,16 & 0,32 & 25,00 & \\
Biópsia 12 meses & 1,21 & 0,32 & 26,71 & \\
\hline
\end{tabular}

teste não-paramétrico de Kruskal-Wallis

Tabela 6. Comparação da relação entre o comprimento da camada basal e superficial do epitélio, entre tempos, no grupo álcool tópico.

\begin{tabular}{lcccc}
\hline Biópsia & Média & Desvio-Padrão & Rank Médio & p \\
\hline Biópsia Inicial & 1,00 & 0,22 & 20,74 & 0,03 \\
Biópsia 6 meses & 1,05 & 0,18 & 24,82 & \\
Biópsia 12 meses & 1,27 & 0,36 & 34,00 & \\
\hline
\end{tabular}

*Médias seguidas de mesma letra não diferem entre si.

teste não-paramétrico de Kruskall-Wallis

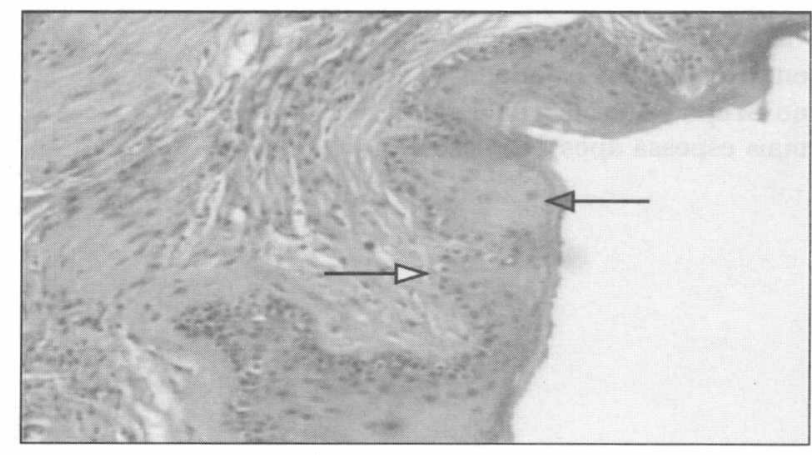

Fotomicrografia de lâmina do Grupo Álcool Tópico, momento 12 meses, onde observa-se a camada basal (seta clara) bastante maior em relação à camada superficial do epitélio (seta escura). $H E, 320 X$. 


\section{CERATINA}

- ESTUdO DA ESPESSURA DE

A mensuração desta espessura é entendida por nós como um indicador do índice de descamação do epitélio, quanto menor o valor, menor é a espessura da camada de ceratina e indica um alto índice de descamação.

Através dos resultados do teste nãoparamétrico de Kruskal-Wallis, não foram verificadas diferenças estatísticas significativas com relação à espessura da ceratina entre os grupos estudados, no tempo inicial.

Através dos resultados do teste nãoparamétrico de Kruskal-Wallis, foram verificadas diferenças estatísticas significativas com relação à espessura da ceratina entre os grupos estudados. Observa-se que o Grupo Controle apresentou espessura maior após 6 meses. $(p=0,01)$
Tabela 7. Comparação da espessura da ceratina, entre os grupos, no momento inicial.

\begin{tabular}{lcccc}
\hline Grupo & Média & Desvio-Padrão & Rank Médio & p \\
\hline Controle & 22,39 & 5,13 & 24,72 & 0,339 \\
Álcool Contínuo & 23,27 & 5,17 & 26,83 & \\
Álcool Tópico & 26,54 & 7,79 & 32,21 & \\
\hline
\end{tabular}

Tabela 8. Comparação da espessura da ceratina, entre os grupos, no momento 6 meses

\begin{tabular}{|lcccc|}
\hline Grupo & Média & Desvio-Padrão & Rank Médio & p \\
\hline Controle & 31,74 & 6,35 & $35,75^{\mathrm{A}}$ & 0,01 \\
Álcool Contínuo & 24,15 & 4,81 & $17,94^{\mathrm{B}}$ & \\
Álcool Tópico & 25,09 & 6,15 & $21,53^{\mathrm{B}}$ & \\
\hline
\end{tabular}

* Médias seguidas de mesma letra não diferem entre si.

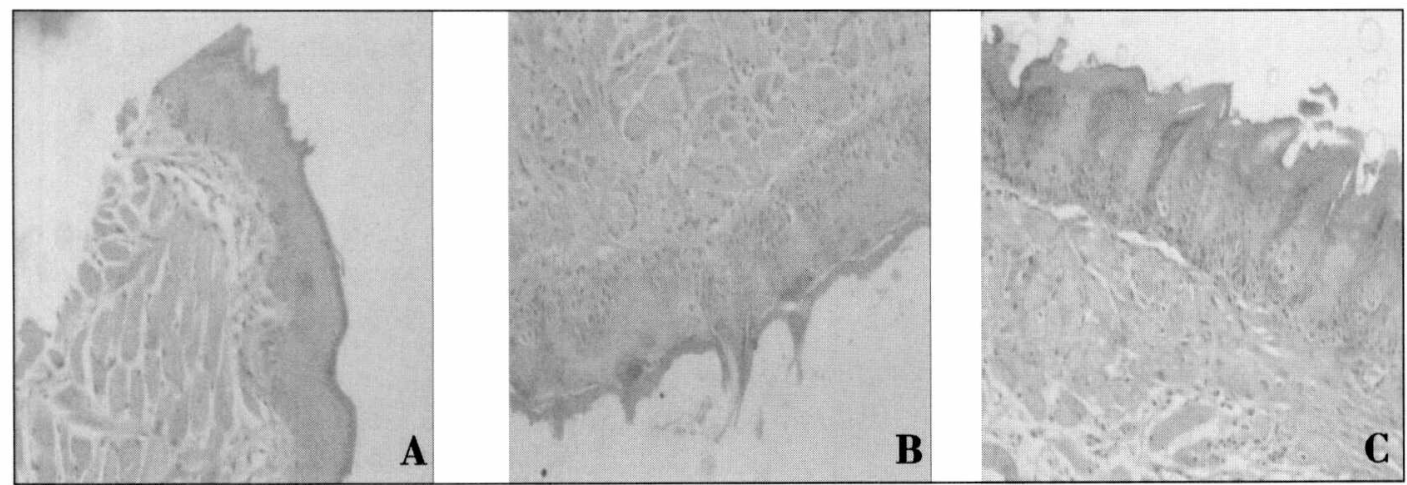

Fotomicrografias das lâminas utilizadas para o cálculo da espessura de ceratina dos Grupos (A) Álcool Contínuo, (B) Álcool Tópico e (C) Controle, aos 6 meses. HE, $320 X$
Através dos resultados do teste nãoparamétrico de Kruskal-Wallis, foram verificadas diferenças estatísticas significativas com relação à espessura da ceratina entre os grupos estudados. Observa-se que no Grupo Controle a camada de ceratina era mais espessa após 12 meses. $(p=0,01)$
Tabela 9. Comparação da espessura da ceratina, entre os grupos, no momento 12 meses

\begin{tabular}{lcccc}
\hline Grupo & Média & Desvio-Padrão & Rank Médio & p \\
\hline Controle & 29,82 & 7,74 & $33,71^{\mathrm{A}}$ & 0,01 \\
Álcool Contínuo & 22,51 & 3,69 & $19,36^{\mathrm{B}}$ & \\
Álcool Tópico & 21,23 & 7,30 & $15,80^{\mathrm{B}}$ & \\
\end{tabular}

* Médias seguidas de mesma letra não diferem entre si.

Fotomicrografias das lâminas utilizadas para o cálculo da espessura de ceratina dos Grupos (A) Álcool Contínuo, (B) Álcool Tópico $e(C)$ Controle, aos 12 meses. HE, $320 X$

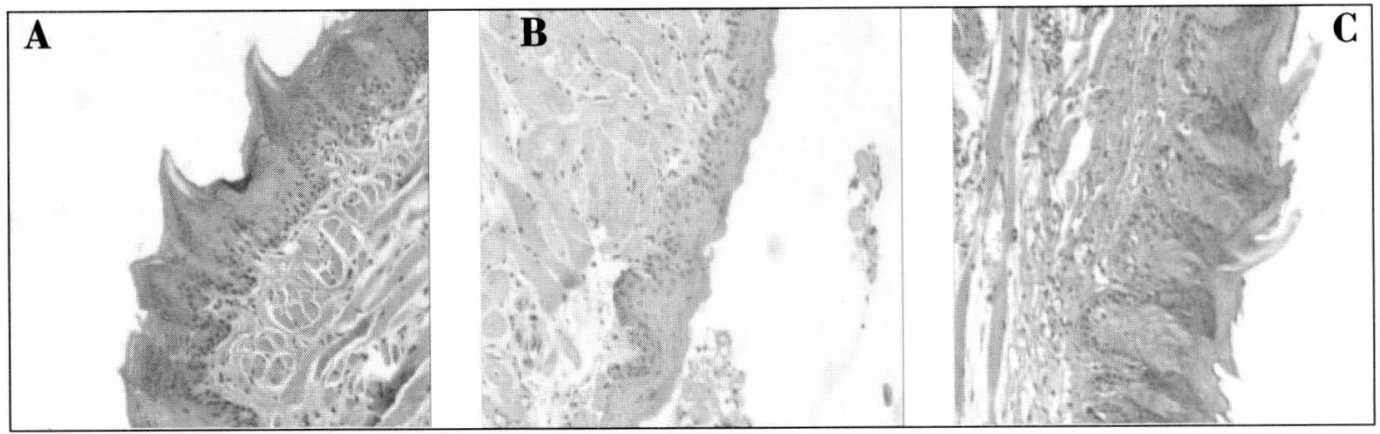


Através dos resultados do teste nãoparamétrico de Kruskal-Wallis, foram verificadas diferenças estatísticas significativas considerando a espessura da ceratina do Grupo Controle nos diferentes tempos do experimento. Observa-se que na biópsia inicial a espessura da ceratina era menor e que a mesma foi aumentando até os seis meses, não havendo, no entanto diferença significativa entre os valores encontrados no $6^{\circ}$ e $12^{\circ}$ mês. $(p=0,01)$
Tabela 10. Comparação da espessura da ceratina, entre os tempos, no grupo controle

\begin{tabular}{|lcccc|}
\hline Biópsia & Média & Desvio-Padrão & Rank Médio & p \\
\hline Biópsia Inicial & 22,39 & 5,13 & $14,06^{\mathrm{A}}$ & 0,01 \\
Biópsia 6 meses & 31,74 & 6,36 & $34,94^{\mathrm{B}}$ & \\
Biópsia 12 meses & 29,82 & 7,74 & $30,24^{\mathrm{B}}$ & \\
\hline
\end{tabular}

* Médias seguidas de mesma letra não diferem entre si.
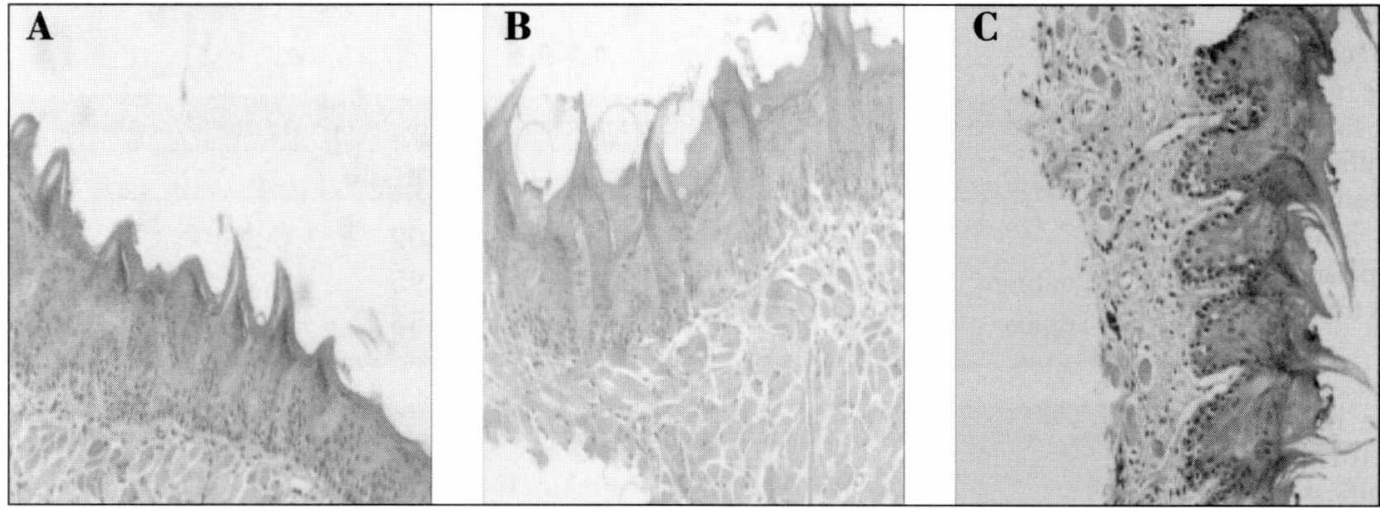

Fotomicrografias das lâminas utilizadas para o cálculo da espessura de ceratina do Grupo Controle no (A) momento inicial, (B) aos 6 meses e $(C)$ aos 12 meses. $\mathrm{HE}, 320 \mathrm{X}$

Através dos resultados do teste nãoparamétrico de Kruskal-Wallis, não foram verificadas diferenças estatísticas significativas considerando a espessura da ceratina nos animais que foram submetidos à ingestão contínua de álcool em diferentes momentos de análise.
Tabela 11. Comparação da espessura da ceratina, entre os tempos, no grupo álcool contínuo

\begin{tabular}{|lcccc}
\hline Biópsia & Média & Desvio-Padrão & Rank Médio & p \\
\hline Biópsia Inicial & 23,27 & 5,18 & 23,50 & 0,50 \\
Biópsia 6 meses & 24,15 & 4,81 & 27,75 & \\
Biópsia 12 meses & 22,51 & 3,69 & 22,07 & \\
\hline
\end{tabular}

Fotomicrografias utilizadas para o cálculo da espessura de ceratina do Grupo Álcool Contínuo (A) no momento inicial e (B) aos 12 meses. $H E, 320 X$
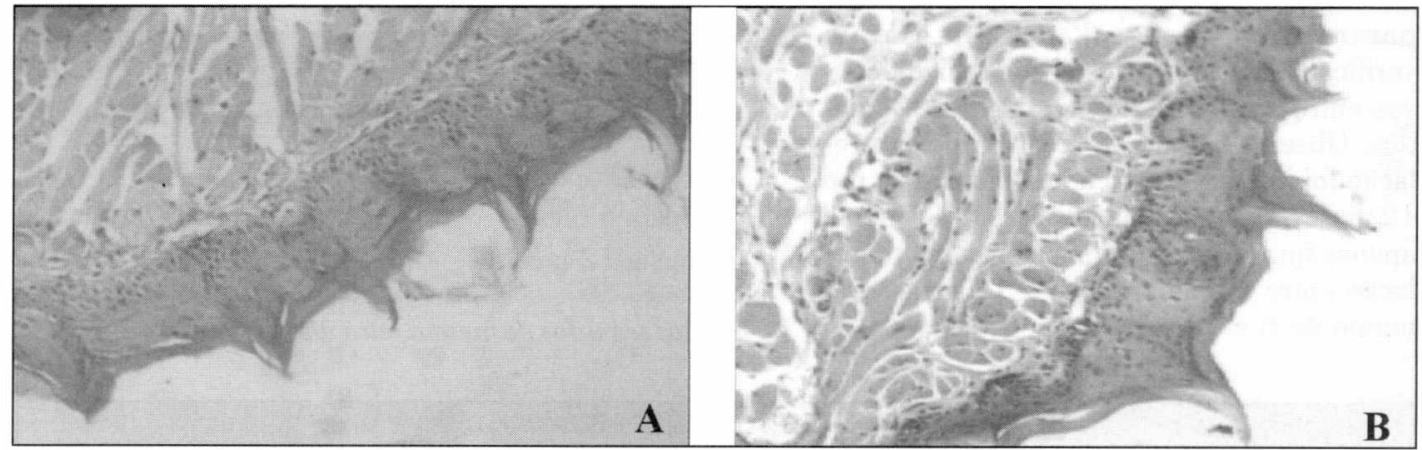

Através dos resultados do teste nãoparamétrico de Kruskall-Wallis, foram verificadas diferenças estatísticas significativas com relação à espessura da ceratina para os momentos estudados. Observa-se que o valor da espessura da ceratina é menor na biópsia de 12 meses. Esta observação no diz que a espessura de ceratina é menor ao longo do tempo. $(p=0,05)$
Tabela 12. Comparação da espessura da ceratina, entre os tempos, no grupo álcool tópico

\begin{tabular}{lcccc} 
Biópsia & Média & Desvio-Padrão & Rank Médio & \multicolumn{1}{c}{ p } \\
\hline Biópsia Inicial & 26,54 & 7,80 & $29,37^{\mathrm{A}}$ & 0,05 \\
Biópsia 6 meses & 25,09 & 6,15 & $29,18^{\mathrm{A}}$ & \\
Biópsia 12 meses & 21,23 & 7,30 & $18,13^{\mathrm{B}}$ & \\
\hline
\end{tabular}

* Médias seguidas de mesma letra não diferem entre si. 
Fotomicrografias utilizadas para o cálculo da espessura de ceratina do Grupo Álcool Tópico (A) no momento inicial e (B) aos 12 meses. $\mathrm{HE}, 320 \mathrm{X}$

\section{- RELAÇÃO NÚCLEO-CITOPLASMA}

A relação núcleo-citoplasma nos mostra a proporção do tamanho do núcleo em relação ao tamanho do citoplasma e é considerada pela razão entre a área do núcleo e a área do citoplasma. É entendido que esta relação aumentada indica um núcleo mais ativo, mais produtivo e pode ser relacionada esta informação com atividade celular (nuclear) aumentada, que pode ser no sentido de proliferação.

Através dos resultados do teste nãoparamétrico de Kruskal-Wallis, não foram verificadas diferenças estatísticas significativas entre a relação entre os grupos estudados. Estes resultados mostram não haver diferença quanto a relação núcleo-citoplasma entre os grupos no momento inicial do trabalho experimental.

Através dos resultados do teste nãoparamétrico de Kruskal-Wallis, foram verificadas diferenças estatísticas significativas entre a relação nos grupos estudados. Observa-se que o Grupo Controle apresentou valores superiores, o que é entendido como aumento da atividade nuclear. $(\mathrm{p}=0,01)$

Através dos resultados do teste nãoparamétrico de Kruskal-Wallis, não foram verificadas diferenças estatísticas significativas entre a relação nos grupos estudados. Observa-se nesta Tabela que os valores das médias nos três grupos foram muito próximas.

Através dos resultados do teste nãoparamétrico de Kruskal-Wallis, foram verificadas diferenças estatísticas significativas entre a relação entre os grupos estudados. Observa-se que na biópsia inicial a relação foi inferior à relação na biópsia de $6 \mathrm{e}$ 12 meses, sendo significativa estatisticamente apenas quando comprados os valores da relação entre o tempo inicial e 12 meses e o tempo de 6 e 12 meses. $(p=0,01)$

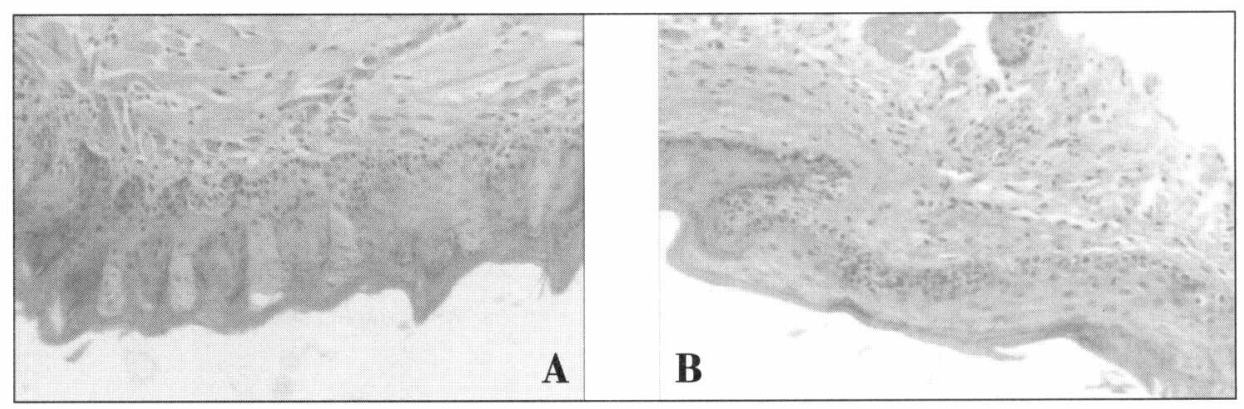

Tabela 13. Comparação da relação núcleo-citoplasma, entre os grupos, no momento inicial

\begin{tabular}{|lcccc}
\hline Grupo & Média & Desvio-Padrão & Rank Médio & p \\
\hline Controle & 0,46 & 0,11 & 83,02 & 0,26 \\
Álcool Contínuo & 0,49 & 0,15 & 89,95 & \\
Álcool Tópico & 0,50 & 0,12 & 98,53 & \\
\hline
\end{tabular}

Tabela 14. Comparação da relação núcleo-citoplasma, entre os grupos, no momento 6 meses

\begin{tabular}{lcccc}
\hline Grupo & Média & Desvio-Padrão & Rank Médio & p \\
\hline Controle & 0,51 & 0,09 & $106,70^{\mathrm{A}}$ & 0,01 \\
Álcool Contínuo & 0,46 & 0,13 & $83,28^{\mathrm{B}}$ & \\
Álcool Tópico & 0,45 & 0,12 & $81,52^{\mathrm{B}}$ & \\
\hline
\end{tabular}

* Médias seguidas de mesma letra não diferem entre si.

Tabela 15. Comparação da relação núcleo-citoplasma, entre os grupos, no momento 12 meses

\begin{tabular}{lcccc}
\hline Grupo & Média & Desvio-Padrão & Rank Médio & p \\
\hline Controle & 0,55 & 0,14 & 97,25 & 0,46 \\
Álcool Contínuo & 0,50 & 0,09 & 87,82 & \\
Álcool Tópico & 0,52 & 0,19 & 86,43 & \\
\hline
\end{tabular}

Tabela 16. Comparação da relação núcleo-citoplasma, entre os tempos, no grupo controle

\begin{tabular}{lcccc}
\hline Biópsia & Média & Desvio-Padrão & Rank Médio & p \\
\hline Biópsia Inicial & 0,46 & 0,11 & $71,85^{\mathrm{A}}$ & 0,01 \\
Biópsia 6 meses & 0,51 & 0,09 & $93,97^{\mathrm{AB}}$ & \\
Biópsia 12 meses & 0,55 & 0,14 & $105,68^{\mathrm{B}}$ & \\
\hline
\end{tabular}

* Médias seguidas de mesma letra não diferem entre si.
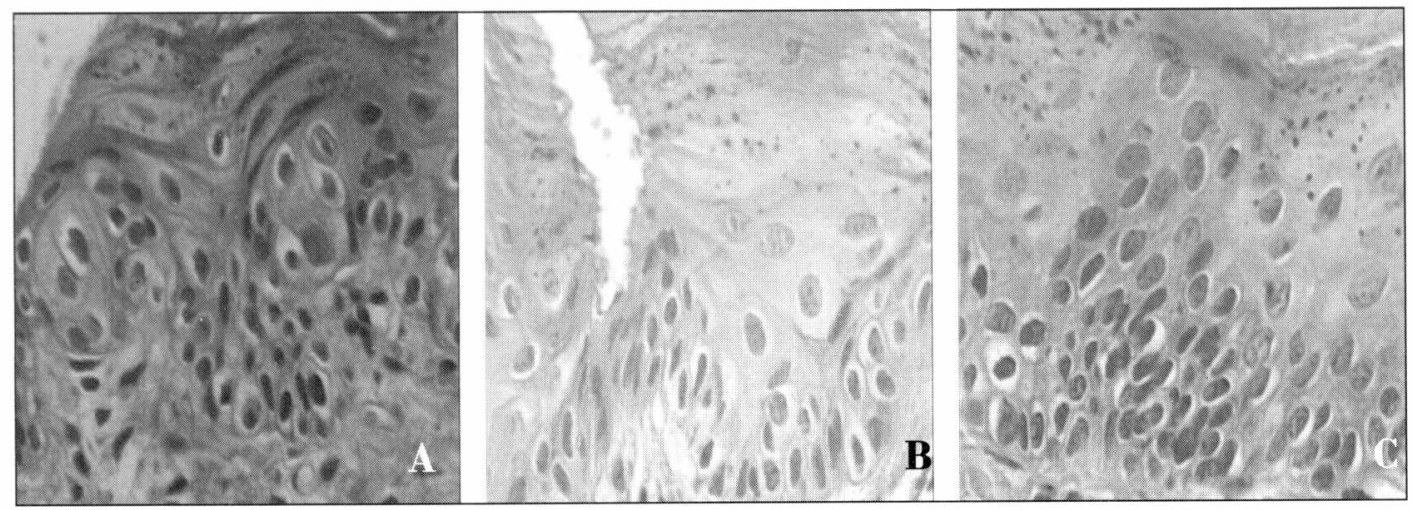

Fotomicrografias utilizadas para o cálculo da relação núcleo citoplasma no Grupo Controle: (A) inicial, (B) 6 meses e (C) 12 meses. HE, $400 X$ 
Através dos resultados do teste nãoparamétrico de Kruskall-Wallis, foram verificadas diferenças estatísticas significativas entre a relação para os momentos estudados. Observa-se que o valor da relação é superior na biópsia de 12 meses. Este fato sugere que as alterações celulares em animais expostos ao álcool talvez só possam ser avaliadas após mais de 6 meses de exposição. $(p=0,02)$
Tabela 17. Comparação da relação núcleo-citoplasma, entre os tempos, no grupo álcool contínuo

\begin{tabular}{lcccc}
\hline Biópsia & Média & Desvio-Padrão & Rank Médio & p \\
\hline Biópsia Inicial & 0,49 & 0,15 & $87,97^{\mathrm{A}}$ & 0,02 \\
Biópsia 6 meses & 0,46 & 0,13 & $79,03^{\mathrm{A}}$ & \\
Biópsia 12 meses & 0,50 & 0,09 & $104,50^{\mathrm{B}}$ & \\
\hline
\end{tabular}

* Médias seguidas de mesma letra não diferem entre si.

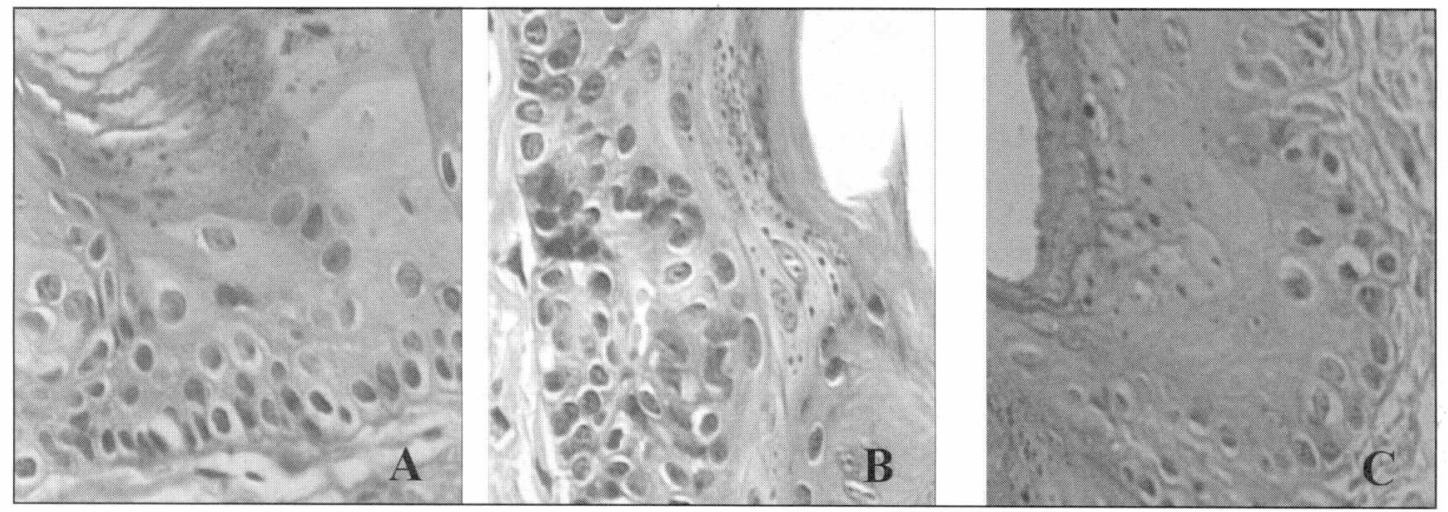

Fotomicrografias utilizadas para o cálculo da relação núcleo citoplasma no Grupo Álcool Contínuo: (A) inicial, (B) 6 meses e (C) 12 meses. $H E, 400 X$

Através dos resultados do teste nãoparamétrico de Kruskall-Wallis, não foram verificadas diferenças estatísticas significativas entre a relação para o grupo estudado, nos momentos estudados, mas observa-se que a relação sofreu uma redução entre o momento inicial e o dos 6 meses, voltando a elevar-se entre os 6 e os 12 meses do experimento.
Tabela 18. Comparação da relação núcleo-citoplasma, entre os tempos, no grupo álcool tópico

\begin{tabular}{lcccc}
\hline Biópsia & Média & Desvio-Padrão & Rank Médio & p \\
\hline Biópsia Inicial & 0,50 & 0,12 & 95,77 & 0,09 \\
Biópsia 6 meses & 0,45 & 0,12 & 78,62 & \\
Biópsia 12 meses & 0,52 & 0,19 & 97,12 & \\
\hline
\end{tabular}

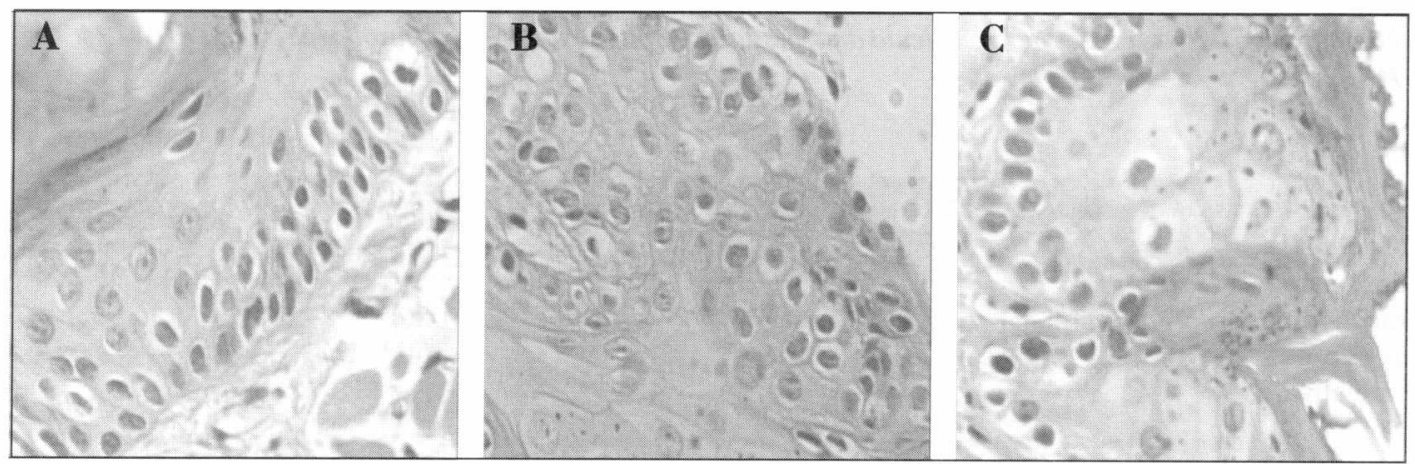

Fotomicrografias utilizadas para o cálculo da relação núcleo citoplasma no Grupo Álcool Tópico: (A) inicial, (B) 6 meses e (C) 12 meses. $\mathrm{HE}, 400 \mathrm{X}$

\section{EPITÉLIO}

ESTUDO DA ESPESSURA DO

A mensuração desta espessura do epitélio é entendida por nós como um indicador do índice de proliferação do epitélio ao longo do tempo e foi calculada através de medições realizadas entre o limite da camada basal e a superfície mais externa da camada de ceratina, sempre de forma perpendicular à camada basal.

Através dos resultados do teste nãoparamétrico de Kruskal-Wallis, não foram verificadas diferenças estatísticas significativas entre a espessura do epitélio entre os grupos estudados. É possível observar que não há diferença significativa entre as espessuras entre os grupos estudados no momento inicial.
Tabela 19. Comparação da espessura do epitélio, entre os grupos, no momento inicial

\begin{tabular}{lcccc}
\hline Grupo & Média & Desvio-Padrão & Rank Médio & p \\
\hline Controle & 0,10 & 0,02 & 33,67 & 0,15 \\
Álcool Contínuo & 0,09 & 0,02 & 23,50 & \\
Álcool Tópico & 0,09 & 0,02 & 28,00 & \\
\hline
\end{tabular}

Tabela 20. Comparação da espessura do epitélio, entre os grupos, no momento 6 meses

$\begin{array}{lcccc}\text { Grupo } & \text { Média } & \text { Desvio-Padrão } & \text { Rank Médio } & \text { p } \\ \text { Controle } & 0,11 & 0,02 & 36,55^{\mathrm{A}} & 0,01 \\ \text { Álcool Contínuo } & 0,09 & 0,01 & 18,06^{\mathrm{B}} & \\ \text { Álcool Tópico } & 0,10 & 0,02 & 26,86^{\mathrm{B}} & \end{array}$

* Médias seguidas de mesma letra não diferem entre si. 
Através dos resultados do teste nãoparamétrico de Kruskal-Wallis, foram verificadas diferenças estatísticas significativas entre a espessura do epitélio entre os grupos estudados. Observa-se que o Grupo Controle apresentou valores superiores, o que demonstra haver este grupo sofrido um espessamento do epitélio durante os primeiros 6 meses do experimento. $(p=0,01)$

Através dos resultados do teste nãoparamétrico de Kruskal-Wallis, foram verificadas diferenças estatísticas significativas entre a espessura do epitélio entre os grupos estudados $(p=0,05)$. Observa-se que o Grupo Controle apresentou valores superiores. Aqui mais uma vez podemos observar que o Grupo Controle sofreu, novamente, um espessamento do epitélio após os primeiros 6 meses do experimento. Comparando-se os dados da Tabela 21 com os apresentados nas Tabelas 19 e 20 observa-se que os grupos que estiveram expostos ao álcool praticamente não modificaram a espessura do epitélio ao longo do tempo experimental.

Através dos resultados do teste não-paramétrico de KruskalWallis, foram verificadas diferenças estatísticas significativas entre a espessura do epitélio entre os grupos estudados. Observa-se que a espessura do epitélio foi aumentando com o passar do tempo. $(p=0,01)$
Tabela 21. Comparação da espessura do epitélio, entre os grupos, no momento 12 meses.

\begin{tabular}{|lcccc|}
\hline Grupo & Média & Desvio-Padrão & Rank Médio & p \\
\hline Controle & 0,12 & 0,03 & $30,47^{\mathrm{A}}$ & 0,05 \\
Álcool Contínuo & 0,10 & 0,01 & $20,07^{\mathrm{B}}$ & \\
Álcool Tópico & 0,10 & 0,02 & $20,56^{\mathrm{B}}$ & \\
\hline
\end{tabular}

* Médias seguidas de mesma letra não diferem entre si.

Tabela 22. Comparação da espessura do epitélio, entre os tempos, no grupo controle.

\begin{tabular}{|lcccc}
\hline Biópsia & Média & Desvio-Padrão & Rank Médio & p \\
\hline Biópsia Inicial & 0,10 & 0,02 & $18,65^{\mathrm{A}}$ & 0,01 \\
Biópsia 6 meses & 0,11 & 0,02 & $31,32^{\mathrm{B}}$ & \\
Biópsia 12 meses & 0,12 & 0,03 & $36,94^{\mathrm{B}}$ & \\
\hline
\end{tabular}

* Médias seguidas de mesma letra não diferem entre si.

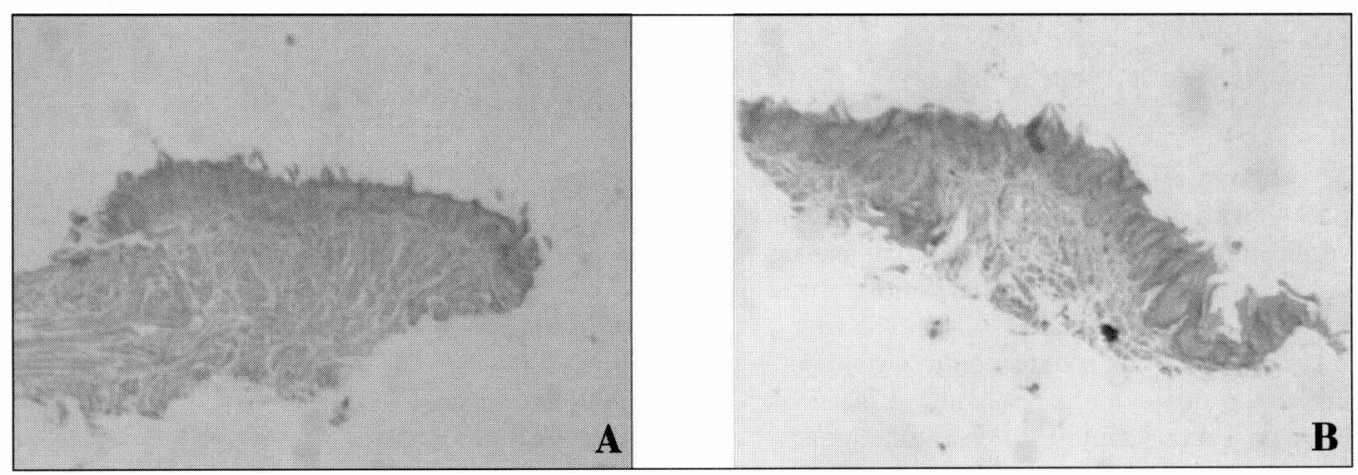

Fotomicrografias utilizadas para o cálculo da espessura do epitélio no Grupo Controle: (A) inicial e (B) 12 meses. HE, $250 X$
Através dos resultados do teste nãoparamétrico de Kruskall-Wallis, observa-se que o valor da espessura do epitélio, neste grupo, praticamente não sofreu alterações ao longo do experimento, mas entre os 6 e os 12 meses houve uma variação significativa estatisticamente $(p=0,01)$.
Tabela 23. Comparação da espessura do epitélio, entre os tempos, no grupo álcool contínuo.

\begin{tabular}{lcccc}
\hline Biópsia & Média & Desvio-Padrão & Rank Médio & p \\
\hline Biópsia Inicial & 0,09 & 0,01 & $20,82^{\mathrm{A}}$ & 0,01 \\
Biópsia 6 meses & 0,09 & 0,01 & $22,09^{\mathrm{A}}$ & \\
Biópsia 12 meses & 0,10 & 0,01 & $36,00^{\mathrm{B}}$ & \\
\hline
\end{tabular}

* Médias seguidas de mesma letra não diferem entre si.

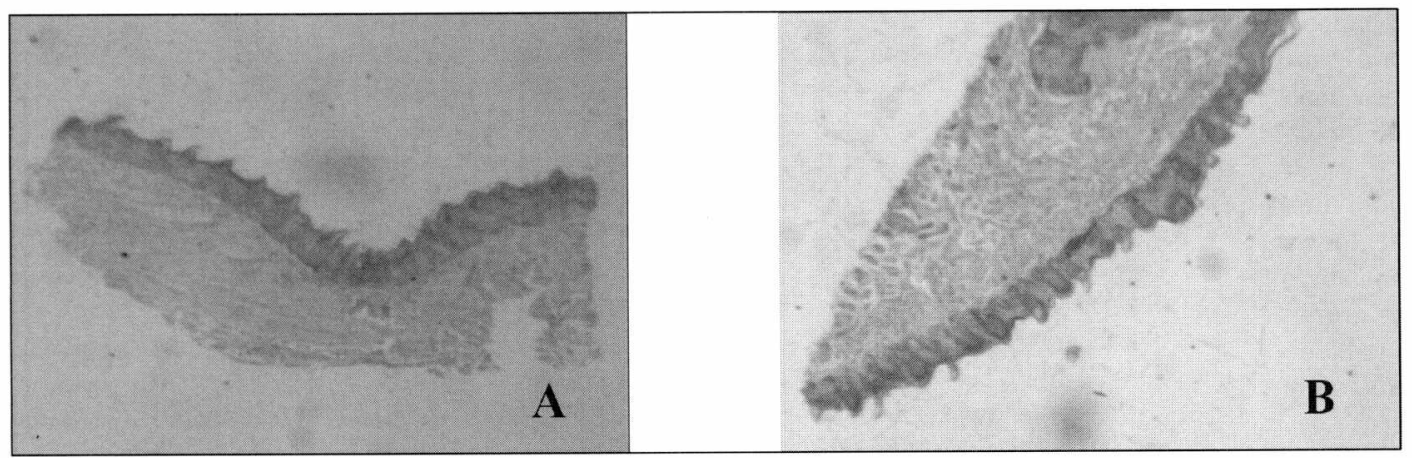

R. Fac. Odontol., Porto Alegre, v. 44, n.1, p. 3-14, jul. 2003
Fotomicrografias utilizadas para o cálculo da espessura do epitélio no Grupo Álcool Contínuo: (A) inicial e (B) 12 meses. $\mathrm{HE}, 250 \mathrm{X}$ 
Através dos resultados do teste nãoparamétrico de Kruskall-Wallis, não foram verificadas diferenças estatísticas significativas entre a espessura do epitélio para os momentos estudados, neste grupo. Pode-se observar que os valores de espessura do epitélio praticamente são os mesmos nos três tempos avaliados.
Tabela 23Tabela 24. Comparação da espessura do epitélio, entre os tempos, no grupo álcool tópico.

\begin{tabular}{|lcccc}
\hline Biópsia & Média & Desvio-Padrão & Rank Médio & p \\
\hline Biópsia Inicial & 0,09 & 0,02 & 20,82 & 0,18 \\
Biópsia 6 meses & 0,10 & 0,02 & 27,22 & \\
Biópsia 12 meses & 0,10 & 0,02 & 30,13 & \\
\hline
\end{tabular}

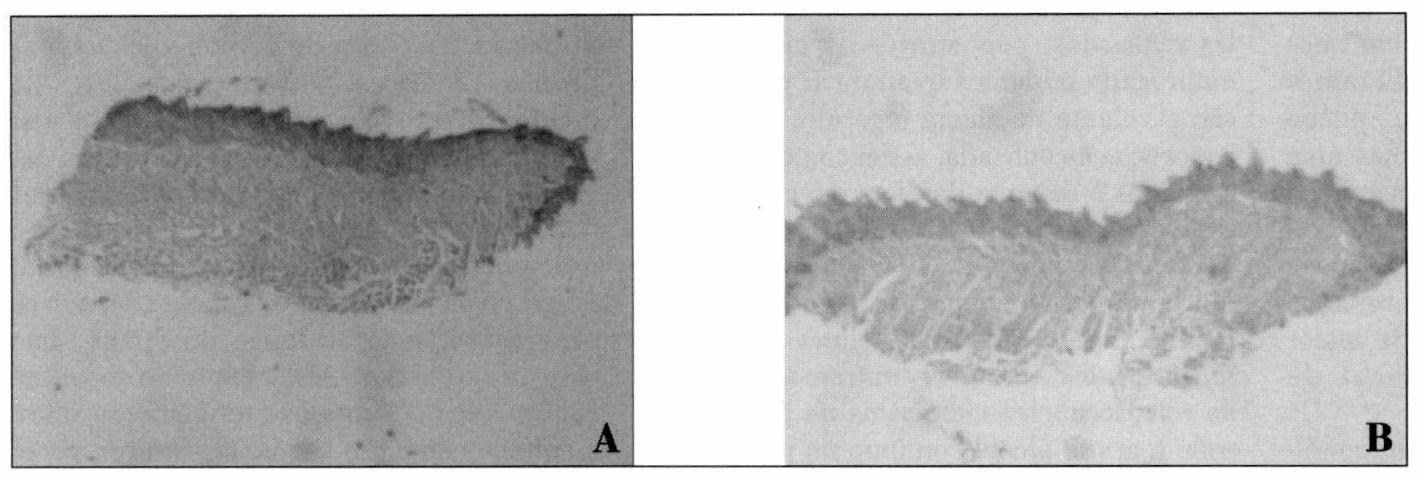

Fotomicrografias utilizadas para o cálculo da espessura do epitélio no Grupo Álcool Tópico: (A) inicial e (B) 12 meses. $\mathrm{HE}, 250 \mathrm{X}$

\section{Discussão}

Alguns autores afirmam que não se pôde ainda demonstrar que o álcool isoladamente, em experimentos laboratoriais, atua como um agente carcinogênico, mas reconhecem que as bebidas alcoólicas são apontadas como um importante fator etiológico no desenvolvimento do câncer bucal, mesmo que ainda não se saiba explicar através de qual mecanismo. Estes mesmos autores ressaltam que devemos considerar que algumas bebidas possuem impurezas e/ou contaminantes que poderiam ser ou agir como carcinógenos. Como utilizamos álcool etílico pró-análise 99\% e água destilada para a preparação do álcool a $40^{\circ} \mathrm{GL}$, podemos afirmar que os resultados encontrados podem ser atribuídos exclusivamente a atuação do álcool sobre o epitélio uma vez que não estivemos expostos ao risco da existência de outras substâncias na mistura (KATO; NOMURA, 1994; OGDEN: WIGTH, 1998 e WIGTH; OGDEN, 1998).

Baseados neste fato podemos embasar o indicativo de Maier e Weidauer (1995), Simanowski et al. (1995), Slomiany et al. (1998) e Ogden e Wigth (1998), de que o álcool isoladamente pode ser apontado como um iniciador da carcinogênese pois as alterações celulares que pode causar ou predispor independe do tipo de bebida consumida estando unicamente na dependência da dose/ frequiência de ingestão. Nossos resultados demonstraram que o álcool isoladamente foi capaz de promover modificações na morfologia do epitélio lingual e estas alterações possivelmente estão relacionadas à modificações celulares ocorridas.

Conforme Maier e Weidauer (1995) e informações do INSTITUTO NACIONAL DO CÂNCER (2000) os efeitos do álcool se verificam dependendo da freqüência de ingestão, da quantidade de alimentos consumidos e do peso corporal. Pudemos avaliar todos estes itens durante todo o período do experimento e encontramos alterações decorrentes do uso do álcool - grupo álcool contínuo e grupo álcool tópico - independentemente da freqüência de ingestão de álcool a $40^{\circ} \mathrm{GL}$, da quantidade de alimentos consumidos e do peso corporal dos animais utilizados neste trabalho. Este fato vem novamente reforçar a idéia de que o álcool de modo isolado pode ser responsabilizado pelas modificações encontradas no epitélio lingual.

Squier, Cox e Hall (1986) e Du et al. (2000) relatam ser maior o risco para aqueles que ingerem bebidas em baixas concentrações $(5 \%)$, baseados nos resultados de seus trabalhos experimentais - in vitro - onde encontraram um aumento da permeabilidade da mucosa quando utilizaram esta concentração alcoólica. Estes autores discutem a possibilidade de, em uma concentração mais elevada - eles utilizaram $50 \%$ de etanol haver uma fixação do epitélio, fato que dificultaria a penetração do etanol. Ao contrário destes trabalhos, mesmo que neste estudo tenha sido avaliado um sítio diferente (dorso de língua ao invés de assoalho bucal), foram verificadas, por nós, alterações morfológicas utilizando-se a graduação de $40^{\circ} \mathrm{GL}$. $\mathrm{O}$ fato de termos utilizado um modelo animal e não pesquisa in vitro como os autores citados demonstra a importância de estudos in vivo onde as condições de ingestão e meio-ambiente bucal podem ser controladas e/ou reproduzidas. A metodologia por nós utilizada por si explica as diferenças encontradas com os autores acima. Do mesmo modo, poderia se dizer que as concentrações são semelhantes mas não iguais e que talvez a fixação sugerida somente comece a aparecer numa concentração igual ou maior que $50 \%$. Isto indicaria que o álcool pode atuar de diferentes formas sobre o epitélio da mucosa bucal.

Os resultados encontrados por nós indicam o que vários autores já indicavam (BOFFETA et al., 1992; MAIER; WEIDAUER, 1995; SIMANOWSKI et al., 1995; SLOMIANY et al., 1998; OGDEN; WIGTH, 1998; WIGTH; OGDEN, 1998; MAIER et al., 1999): o etanol (álcool etílico) pode ser considerado como o responsável isoladamente pelo aparecimento/desenvolvimento de alterações celulares que podem indicar o início da carcinogênese. Conforme estes autores independentemente do tipo de bebida consumida podemos ter alterações celulares que podem levar ao desenvolvimento de um câncer. Este fato é apoiado por nossos resultados uma vez que pudemos observar alterações morfológicas no epitélio que decorrem de alterações no comportamento das células que o compõe o que indicaria estarem estas sofrendo mudanças que poderiam ser relacionadas com o desenvolvimento de um comportamento anômalo.

Nossa metodologia e os resultados obtidos nos levam a crer que os efeitos tóxicos do álcool estão relacionados à sua atuação direta e sistêmica sobre a mucosa bucal, em especial no que diz respeito à proliferação desta. Baseados nos resultados verificados tanto no grupo álcool contínuo quanto no gru- 
po álcool tópico pudemos constatar que nestes grupos houve uma redução na espessura do epitélio, quando comparados ao grupo controle. Alguns autores já haviam relatado tais resultados indicando que esta redução da espessura epitelial poderia estar relacionada a uma maior atuação de carcinógenos químicos (KATO; NOMURA, 1994; MAIER et al., 1994; WIGTH; OGDEN, 1998).

Do mesmo modo que Maier et al. (1999), que estudaram o efeito do consumo de álcool sobre a mucosa da glote em ratos e Oliveira et al. (1994), que avaliaram o resultado do alcoolismo materno no epitélio lingual de fetos de ratos, encontramos uma significativa redução na espessura do epitélio na região estudada (dorso de língua) nos grupos consumidores de álcool e concordamos com as suas conclusões de que esta redução pode significar uma "suscetibilidade maior na direção de uma atuação local de carcinógenos químicos".

Maier et al. (1994) concluíram que o álcool, através de seu uso crônico, causa uma atrofia na mucosa bucal, especialmente a da língua, associada a uma proliferação mais intensa posterior, fato corroborado pelo aumento na descamação do epitélio lingual, conforme visto por Larentis et al. (2000). Nossos resultados apoiam os de Maier et al. (1994), pois verificamos que o epitélio da língua dos grupos expostos ao álcool não sofreram espessamento ao longo do tempo como os do grupo controle. Já no tempo de 6 meses do experimento foi possível constatar-se o não crescimento em espessura do epitélio da língua dos animais do grupo álcool contínuo e grupo álcool tópico. Aos 12 meses foi verificado que o epitélio manteve-se com espessura menor (Tabelas 21 e 22), nos dois grupos em relação ao grupo controle (GC).

Ao mesmo tempo nossos resultados foram diferentes dos achados de Homann et al. (1997) que verificou hiperplasia e hiperproliferação do trato gastrintestinal superior, incluindo a língua, após administração de aldeído na mucosa bucal por 8 meses. O fato destes autores terem feito uso do aldeído, que é derivado do metabolismo tecidual do álcool, e referido como um elemento mais tóxico do que o acetaldeído que é o primeiro estágio da metabolização do álcool no fígado pode explicar esta diferença com o presente trabalho. Talvez por termos utilizado o álcool na graduação de $40^{\circ} \mathrm{GL}$ não tenhamos observado hiperplasia nem hiperproliferação em função da atuação e metabolismo deste ser diferente da do aldeído. Dessa forma pudemos verificar que o álcool não promoveu a hiperplasia ou hiperproliferação do epitélio da mucosa lingual, tanto na espessura do epitélio quanto na espessura da camada de ceratina naqueles grupos que receberam o álcool de forma continuada ou em aplicações tópicas.

Wigth e Ogden (1998) afirmam ser impossível avaliar-se o papel do álcool na carcinogênese, em humanos, por não se poder medir com precisão a quantidade e o tipo de bebida consumida, assim como os itens da dieta alimentar. Ao utilizarmos um modelo animal pudemos avaliar a atuação do álcool em alterações morfológicas do epitélio lingual através da análise dos controles realizados, pois através da metodologia empregada pudemos quantificar com precisão o volume de álcool ingerido, o tipo e a concentração utilizada, assim como dispomos de dados à respeito da dieta e o controle da evolução do peso dos animais.

Simanowski et al. (1995), após análise morfométrica encontraram aumento no tamanho dos núcleos das células basais da mucosa bucal, e nós encontramos aumento na relação núcleo-citoplasma no grupo controle e grupo álcool contínuo no período de 12 meses, no grupo álcool tópico a variação não foi significativa.

Nossos resultados são comparáveis aos de Ogden, Wigth e Rice (1999) quando avaliados os resultados da relação núcleocitoplasma no tempo de 06 meses do experimento, quando também encontramos uma significativa redução desta relação nos grupos consumidores de álcool (grupo álcool contínuo e grupo álcool tópico) comparados ao grupo controle. Ao final do experimento (12 meses) é o grupo controle que apresenta a maior relação comparado aos demais grupos. Da mesma forma outros estudos são necessários para se identificar o fator que interferiria na maior atividade nuclear observado nos primeiros 06 meses e menor nos 12 meses nos grupos experimentais.

Não encontramos na literatura consultada qualquer referência quanto à relação entre a camada basal e superficial do epitélio. Este item foi avaliado por nós pois o entendemos como um possível indicador de proliferação. Se a camada basal é maior em comprimento que a camada superficial indica que existe uma grande área de proliferação com menor área de descamação e isto poderia ser um indicativo de atividade celular no sentido da proliferação. Nossos resultados mostram que apenas no grupo álcool tópico houve uma variação significativa durante o período experimental (Tabela 6), mostrando um aumento da relação entre as camadas basal e superficial durante o decorrer do trabalho. Este resultado foi interpretado como sendo o efeito de um maior tempo de permanência do álcool na cavidade bucal destes animais e também o fato de que estes animais recebiam um volume maior de álcool durante as aplicações tópicas do que aquele que era consumido per capita no gru- po álcool contínuo.

Quanto à espessura da camada de ceratina. Supomos que a análise da mesma pode ter quase que o mesmo significado da avaliação da espessura do epitélio, uma vez que a camada de ceratina foi considerada nas medições realizadas para a determinação desta. Analisando-se os resultados entre os grupos (Tabelas 7 a 9) pudemos verificar que diferenças foram vistas apenas nos grupos expostos ao álcool, mostrando uma redução da espessura de ceratina nos tempos de 6 e 12 meses. Quando se analisa esta medida dentro dos grupos observa-se que no grupo controle (Tabela 10) houve um aumento gradual desta espessura com o passar do tempo, o que pode ser interpretado como o comportamento normal e fisiológico. Já, no grupo álcool contínuo (Tabela 11), não se observa variação ao longo do tempo, fato esse atribuído por nós ao efeito do consumo continuado do álcool que teria atuado sobre o epitélio como um agente agressor e, como meio de defesa, este epitélio descamou mais diminuindo a espessura da camada de ceratina.

No grupo álcool tópico (Tabela 12) podese também observar uma redução na espessura da camada de ceratina, mas esta é muito mais acentuada com o passar do tempo do que a que apresentou o grupo álcool contínuo. Neste caso também entendemos este resultado como uma adaptação à agressão exercida pelo álcool, mas devemos observar que, no tempo de 12 meses, a espessura neste grupo é bem menor que no grupo álcool contínuo. Mais uma vez aqui entendemos que este resultado decorre do maior tempo de permanência do álcool na cavidade bucal dos animais durante as aplicações tópicas, bem como do volume recebido a cada vez, quando comparados ao grupo álcool contínuo.

\section{CONCLUSÕES}

Após a análise dos resultados obtidos e frente à literatura consultada, podemos concluir que:

O álcool na graduação de $40^{\circ} \mathrm{GL}$ consumido de forma contínua ou em aplicações tópicas foi capaz de promover alterações morfológicas no epitélio do dorso da língua conforme os itens avaliados:

Relação entre a Camada Basal e Superficial do Epitélio: verificou-se um aumento desta relação no grupo álcool tópico no tempo de 12 meses;

Espessura da Camada de Ceratina: constatou-se diminuição desta nos grupos expostos ao álcool no tempo de 06 e 12 meses, tendo sido maior a redução no grupo álcool tópico ao final dos 12 meses do experimento. No grupo controle observouse o aumento na espessura desta camada 
ao longo do tempo, enquanto que no grupo álcool contínuo não observou-se variação significativa na espessura desde o momento inicial até o final do experimento. No grupo álcool tópico houve uma redução significativa entre a biópsia inicial e a final, não tendo sido significativa entre a inicial e a dos 06 meses;

Relação Núcleo-Citoplasma: verificou-se um aumento desta relação no tempo de 06 meses no grupo controle quando comparado com os grupos experimentais. Quando avaliamos a relação dentro dos grupos entre os tempos observou-se um aumento nesta relação no grupo controle e grupo álcool contínuo apenas;

Espessura do Epitélio: Foi verificada uma ausência de crescimento nesta medida no grupo álcool tópico no tempo de 06 e 12 meses e no grupo álcool contínuo entre o momento inicial e os 6 meses, quando comparados ao grupo controle. O grupo controle apresentou aumento da espessura enquanto o grupo álcool contínuo e o grupo álcool tópico praticamente não modificaram a espessura do epitélio com o passar do tempo.

\section{ABSTRACT}

Alcohol, itself was never pointed as a carcinogen. Literature refers to alcohol as an inductor or as element that would act in synergy with the tobacco in oral cancer development. In order to evaluate the alcohol role in oral cancer carcinogenesis, an experiment with 60 mice divided in three groups - Control, Continuous Alcohol and Topic Application Group - during one year period was accomplished. Animals of all groups were fed with standard rat pellets. The rats from Alcohol Continuos Group have received alcohol $40^{\circ} \mathrm{GL}$ as liquid diet. Topic alcohol application drinking group received water and an application of alcohol $40^{\circ} \mathrm{GL}$ twice a week simulating eventual consumption. Samples from tongue dorsum were obtained at the beginning of the experiment and after every six months. The samples were processed for histological analysis. It was evaluated and changes were measured in the epithelium (epithelium thickness, keratin layer thickness, relationship between epithelium basal layer and superficial layer and relationship of nucleuscytoplasm area (basal and intermediate layer)). Throughout statistical analysis significant changes were found in almost all evaluated items. It was concluded that alcohol could be pointed out as an oral mucosa morphology-changing agent when consumed continuously or topically applied.

\section{Keywords}

Alcohol, tongue morphology, oral mucosa, mount alcohol effects

\section{REFERÊNCIAS}

ASSOCIAÇÃO BRASILEIRA DE NORMAS TÉCNICAS EB-121 Álcool Especificação e Método de Ensaio, 1960. 5 pág.

ASSOCIAÇÃO BRASILEIRA DE NORMAS TÉCNICAS MB-239 Modo de Execução de Ensaios com Álcool, 1957. 9 pág.

ASSOCIACÃO BRASILEIRA DE NORMAS TÉCNICAS NBR 5992 Determinação da Massa Específica e do Teor Alcoólico do Álcool Etílico e suas Misturas com Água - Método de Ensaio, março de 1980. $31 \mathrm{p}$.

ASSOCIACÃO BRASILEIRA DE NORMAS TÉCNICAS NBR 5995 Densímetro para Álcool e suas Misturas com Água - Características - Padronização, dezembro de 1983. 7 p.

AGUIAR, M.S.F.; ARAÚJO, V.C. p53 Protein Expression in Lining Epithelium Adjacent to Oral Squamous Cell Carcinoma, Rev. Pós-Grad. Fac. Odontol. UFMG, Belo Horizonte, v. 4, n. 1, p. 14-19, 1997

ALBERTS, B. et al. Câncer. In: Biologia Molecular da Célula. São Paulo: Artes Médicas, 1997. 1362 p. 12551291

ATHANÉ, B. Graduação Alcoólica de Gay-Lussac. [mensagem pessoal] mensagem recebida por <sanfelic@ufrgs.br> em 06.jul.2000

BAKER, J.F. A Review of the Importance of the p53 Gene in Cancer Research.[on line] Disponível em: < http://www.aye.net/ jfbaker/ p53.html > acesso em: 11. jun. 2000.

BOFFETA, P. et al. Carcinogenic Effect of Tobacco Smoking and Alcohol Drinking on Anatomic Sites of the Oral Cavity and Oropharynx. Int. J. Cancer, v. 52, no. 4, p.530-533, 1992

BORN, I.A. et al. Effects of Chronic Alcohol Drinking on Mouth Mucosa. A Morphometric Study. Laryngol, v.75, no. 12, p.754-8, 1996

DAY, G.L.; BLOT, W.J. Second Primary Tumors in Patients with Oral Cancer. Cancer, v. 70, no. 1, p. 14-9, 1992

DELEYIANNIS, F.W. et al. Alcoholism: Independent Predictor of Survival in Patients with Head and Neck Cancer. J.
Nat. Cancer Inst., v. 88, no. 8, p.542549, 1996

DU, X. et al. Penetration of Nnitrosonornicotine (NNN) Across Oral Mucosa in the Presence of Ethanol and Nicotine. J. Oral Pathol. Med., v. 29, no. 2, p. 80-85, 2000.

FAWCETT, D.W. Oral Cavity and Associated Glands. In: A Text Book of Histology. 12n ed. New York: Chapman \& Hall, 1994. Cap. 2 p.559-577

FRANCO, E. L. F. Epidemiology of Cancers of the Upper Respiratory and Digestive System. Rev. Brasil. Cir. Cabeça e Pescoço, v. 11 , no. $1 / 3$, p.2333, jan./dez. 1987

GOLDIM, J. R. Pesquisa em Saúde: Leis, Normas e Diretrizes 3.ed. Porto Alegre:GSIS/HCPA, 1997. 156p.

HOMMAN, N. et al. Effects of Acetaldehyde on Cell Regeneration and Differentiation of the Upper Gastrointestinal Tract Mucosa. J. Natl. Cancer Inst., Cary, v. 89, p. 1692-1697, 1997.

HUNG, J.; ANDERSON, R. p53: Functions, Mutations and Sarcomas Acta Orthop Scand., no. 273, Suppl., p. 6873,1997

INSTITUTO NACIONAL DO CÂNCER. Alcoolismo Consumo e Relação com o Câncer, Disponível em: <http:// www.inca.org.br/cancer $>$ Acesso em: 11. Jun. 2000

KATO, I.; NOMURA, A.M.Y. Alcohol in the Aetiology of Upper Aerodigestive Tract Cancer. Oral Onc. Eur. J. Cancer, Oxford, v.30B, n 2, p.75-81, 1994.

KUYAMA, K.; YAMAMOTO, H. A Study of Effects of Mouthwash on the Human Oral Mucosae: With Special References to Sites, Sex Differences and Smoking J. Nihon Univ. Sch. Dent., v. 39, no. 4, p. 202-210, 1997

KRUPALA, J.L.; GIANOLI, G.J. Carcinoma of the Oral Tongue. J. La St. Med. Soc., v. 145 , no. 10 , p. $421-2,425-6$, 1993

LARENTIS, C.L. et al. Avaliação Citopatológica da Mucosa Bucal de Camundongos Fêmeas Submetidos ao Consumo e Aplicação Tópica de Álcool. In: XII SALÃO DE INICIAÇÃO CIENTÍFICA, 13., 2000, Porto Alegre. Anais... Porto Alegre: UFRGS, 2000 
MACLUSKEY, M. et al. The Association Between Epithelial Proliferation and Disease Progression in the Oral Mucosa, Oral Oncol., v. 35, p. 409-414, 1999

MAIER, H. et al. Effect of Chronic Alcohol Consumption on the Morphology of the Oral Mucosa. Alcohol Clin. Experim. Res., v. 18, no. 2, p. 387 391,1994

MAIER, H.; WEIDAUER, H. Alcohol Drinking and Tobacco Smoking are the Chief Risk Factors for ENT Tumors. Increased Incidence of Mouth Cavity, Pharyngeal and Laryngeal Carcinomas. Fortschr Med., v.113, no. 11, p.157160, 1995

MAIER, H. et al. Alcohol Drinking and Cancer of the Upper Aerodigestive Tract in Women. Doutsche Med. Wochenschr, v. 124, no. 28-29, p. 8514, 1999a

MAIER, H. et al. An Association of Chronic Alcohol Consumption with Morphological Alterations of the Laryngeal Mucosa in Rats. Eur. Arch. Otorhinolaryngol., v.256, no. 5, p. 247-9, 1999b

MIKAMI, K.; HASEBA, T.; OHNO, Y. Ethanol Induces Transient Arrest of Cell Division ( $\mathrm{G}+\mathrm{M}$ Block) Followed by $\mathrm{G} /$ $G$ Block: Dose Effects of Short- and Longer-term Ethanol Exposure on Cell Cycle and Cell Functions. Alcohol \& Alcohol., v. 32, no. 2, p.145-152, 1997

OGDEN, G.R.; WIGHT, A.J. Aetiology of Oral Cancer: Alcohol. Br. J. Oral Maxillofac. Surg., v. 36, no. 4, p. 247251, 1998

OGDEN, G.R.; WIGHT, A.J.; COWPE, J.G. Quantitative Oral Exfoliative Citology. Effect of Alcohol on Normal Buccal Mucosa. Analise Quant. Cytol. Histol., v. 21, no. 2, p. 126-130, 1999

OGDEN, G.R.; WIGHT, A.J.; RICE, P. Effect of Alcohol on the Oral Mucosa Assessed by Quantitative Cytomorphometry. J. Oral Pathol. Med., v. 28, n ${ }^{0}$ 5, p. 216-20, 1999

OLIVEIRA, C. et al. Efeitos da Injeção Materna de Aguardente de Cana no Epitélio Lingual do Feto de Ratos. Rev. Fac. Odontol. Rib. Preto, v.6, no. 7, p.31-35, 1994

RIVERO-ROSAS, H.; JULIANSANCHEZ, A.; PIÑA, E. Enzymology of
Ethanol and Acetaldehyde Metabolism in Mammals. Arch. Med. Res., Mexico City, v. 28 , no. 4, p.453-471, 1997.

ROSS, M.H.; ROWELL, L.J. Histologia

Texto e Atlas. 2.ed. São Paulo: Panamericana, 1993. Cap. 15 p. 379. 384

RUOSLAHTI, E. How Cancer Spreads, Scient. Am., p. 42-47, Sept. 1996

SIMANOWSKI, U.A. et al. Effect of Alcohol on Gastrointestinal Cell Regeneration as a Possible Mechanism in Alcohol-associated Carcinogenesis. Alcohol, v. 12, no. 2, p. 111-5, 1995

SLOMIANY et al. Induction of Buccal Mucosal Apoptosis with Chronic Alcohol Ingestion. Bioch. Molec. Biol. Int., v.44, no. 2, p.381-389, 1998

SQUIER, C.A.; HILL, M.V. Oral Mucosa In: TEN CATE, A.R. Oral Histology Development, Structure and Function. St. Louis: Mosby, 1994, Cap. 18 p.389-431

SQUIER, C.A.; COX, P.; HALL, B.K. Enhanced Penetration of Nitrosonornicotine Across Oral Mucosa in the Presence of Ethanol. J. Oral Pathol. v. 15 , no. 5 , p. $276-279$

WANNMACHER, C.M.D; DIAS, R.D. Relações entre os constituintes químicos e o meio intracelular - I - Solubilidade e detergência. In:_ Bioquímica fundamental. 5.ed. Porto Alegre: UFRGS, 1979. Cap. 5 p. 51-64

WEINBERG, R.A. How Cancer Arises. Scient. Am., p.32-40, Sept. 1996

WIGHT, A.J.; OGDEN, G.R. Possible Mechanisms by Which Alcohol may Influence the Development of Oral Cancer - A Review. Oral Oncol., v. 34, no. 6, p. $441-7,1998$

\section{Endereço para correspondência:}

Rua Prof. Carvalho de Freitas, 737/204 CEP 91720-090 - Porto Alegre/RS - BR juliosan@terra.com.br 